\title{
Review Article \\ Synthetic Biology: Tools to Design, Build, and Optimize Cellular Processes
}

\author{
Eric Young and Hal Alper \\ Department of Chemical Engineering, The University of Texas at Austin, 1 University Station, C0400, Austin, TX 78712, USA \\ Correspondence should be addressed to Hal Alper, halper@che.utexas.edu
}

Received 5 August 2009; Accepted 28 October 2009

Academic Editor: Ganesh Sriram

Copyright ( $) 2010$ E. Young and H. Alper. This is an open access article distributed under the Creative Commons Attribution License, which permits unrestricted use, distribution, and reproduction in any medium, provided the original work is properly cited.

\begin{abstract}
The general central dogma frames the emergent properties of life, which make biology both necessary and difficult to engineer. In a process engineering paradigm, each biological process stream and process unit is heavily influenced by regulatory interactions and interactions with the surrounding environment. Synthetic biology is developing the tools and methods that will increase control over these interactions, eventually resulting in an integrative synthetic biology that will allow ground-up cellular optimization. In this review, we attempt to contextualize the areas of synthetic biology into three tiers: (1) the process units and associated streams of the central dogma, (2) the intrinsic regulatory mechanisms, and (3) the extrinsic physical and chemical environment. Efforts at each of these three tiers attempt to control cellular systems and take advantage of emerging tools and approaches. Ultimately, it will be possible to integrate these approaches and realize the vision of integrative synthetic biology when cells are completely rewired for biotechnological goals. This review will highlight progress towards this goal as well as areas requiring further research.
\end{abstract}

\section{Introduction}

The central dogma of biology is simply and elegantly stated; however it is less straightforward to engineer, control, and rewire for biotechnological purposes. This difficulty stems from our limited understanding of the multiscale, and often stochastic, operation, and regulation of biological systems [1-3]. Nevertheless, rapid progress in uncovering the basic framework and information flow within the central dogma has helped fuel the current biotechnological revolution. Yet, elucidating the specific components and control mechanisms inherent in this process has lagged significantly [4-6]. This limitation prevents the creation of custom-built cellular factories using modeling and de novo design. However, this limitation is only temporary. Recent advances in high-throughput biology are quickly uncovering the identity and details of these components and control schemes [7-10]. While not yet complete, this global, systems biology approach repeatedly depicts the central dogma as a multistep process subject to exquisite regulatory mechanisms established to maintain cellular homeostasis and to respond to environmental stimuli.
Once our understanding is advanced, it will be possible to synthetically create desired functions at all levels of the central dogma.

The integrative complexity of the central dogma (and biological systems in general) has analogies and parallels to chemical or electrical systems. The rationale for drawing these analogies is twofold: (1) it helps to contextualize the various parts of a cellular process and (2) it facilitates the possible transfer of knowledge between the analogous systems. In this regard, understanding the central dogma processes, the process controls, and the environmental influences within a cell is as vital as understanding analogous components within a traditional chemical factory. Uncovering and studying these components will ultimately lead to a factory-like cellular blueprint - a detailed catalogue of parts, interactions, and functions. Moreover, compiling such a blueprint for all species will expand the number of parts we are able to access, characterize, and employ when trying to design cells and circuits from scratch. Thus, this understanding will enhance our ability to predict, control, and design cellular systems-major tenets in the emerging field of synthetic biology. 


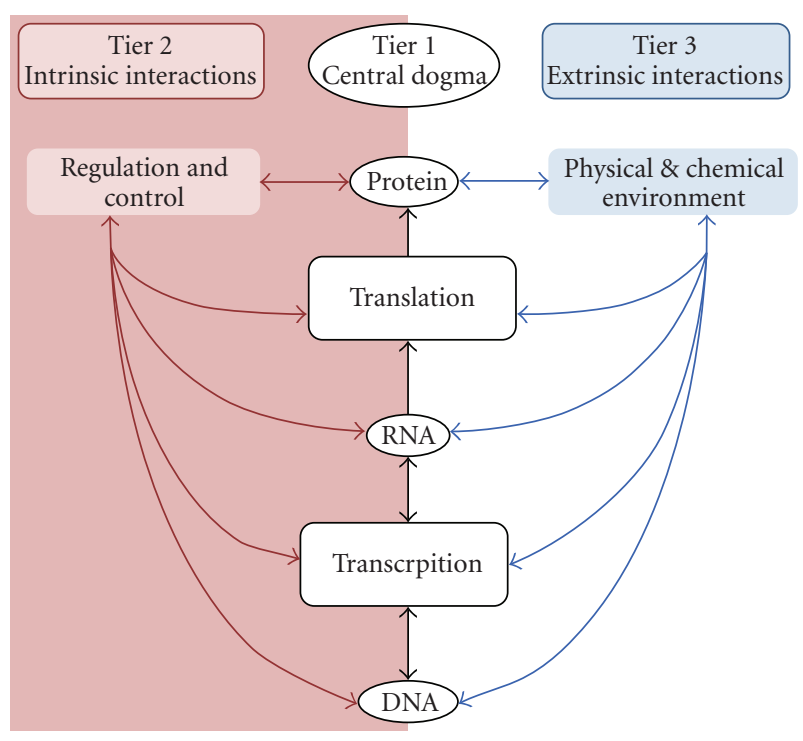

Figure 1: The central dogma with regulatory and environmental influences acting upon the process. The two central dogma process units (transcription and translation) and the three process streams (DNA, RNA, and protein) are depicted. These units and streams are all subject to control by both internal, regulatory and external, environmental conditions. These influences alter the central dogma process and regulatory mechanisms. Large bold arrows are used to indicate that proteins are the major workhorses of the cell, participating both in regulatory mechanisms and responding to the environment. Whether the system of interest is a signaling cascade or metabolic pathway, proteins are essential components and must become well understood and modifiable to bring about groundup cellular optimization. Synthetic biology is developing tools to modify and control each unit and stream in this process.

Due to its youth, the field of synthetic biology has yet to have a concrete, comprehensive definition. Yet, in its broadest sense, synthetic biology aims to harness the emergent properties of the central dogma for biotechnological and human use. This description of the field is comprehensive since even synthetically designed biological circuits actually interface with existing central dogma machinery in the cell. In this regard, tools for synthetic biology harness the complexity of the central dogma process in a predictable, designed fashion.

Within the context of engineering the central dogma, the seemingly wide variety of themes and aims in the synthetic biology research field become more unified. Considering the central dogma as a simple process diagram (Figure 1), it can be seen that the varied areas of synthetic biology research all influence the central dogma albeit at different access points in the process. As Figure 1 illustrates, this system has three tiers, specifically: (1) the central dogma process units (transcription and translation) and associated streams (DNA, RNA, and protein), (2) the intrinsic regulatory mechanisms in the cells, and (3) the extrinsic physical and chemical environment of the cells. These three tiers are depicted separately, but in reality are thoroughly enmeshed with one another as a result of evolved biological complexity. Yet, this very complexity provides a multitude of access points, or nodes, for synthetic biologists to engineer.
Synthetic biology research is at the forefront of engineering the three tiers of biological systems. For example, the newly developed ability to design and chemically synthesize genetic sequences [11-13] provides a greater ability to manipulate DNA, the "feed stream" molecule for the first tier. Contributions from systems biology have broadened our ability to understand and engineer biological networks [14-18], providing impetus for modifying tier two intrinsic control systems and tier three extrinsic signaling interactions. Other frontiers in synthetic biology have greatly expanded our capacity to construct and improve pathways and global cellular phenotype [19-24], which engineers the third tier interaction between proteins and the chemical environment. In the same vein, protein engineering provides the synthetic biologist a great deal of flexibility for introducing and optimizing new function at any node [25-31], since proteins are such universal components throughout the central dogma process. All of these areas of synthetic biology are building toward a single goal: integrative control of the central dogma for biotechnological and human use.

From this viewpoint, developing powerful new tools that manipulate biology at each of the three tiers will empower scientists and engineers with the ability to rewire and program cellular systems for both medical and biotechnological applications. Combining these tools to work in concert would define the field of integrative synthetic biology. This culminating point of synthetic biology development will usher in the age of ground-up cellular design and optimization. However, much of current synthetic biology research is focused on tool development, a required foundation for integrative synthetic biology. As a result, it is not yet clear how to best integrate these approaches. Therefore, the purpose of this review is to provide an overview of synthetic biology research, focusing on microbial hosts, and to highlight areas where more work must be done before realizing the potential of ground-up synthetic cellular engineering.

\section{The First Tier-Process Optimization of the Central Dogma}

The first tier of synthetic biology focuses on altering the general process flow-specifically modifications to the function and behavior of the process units (transcription [32] and translation) and the associated process streams (DNA, RNA [33], and protein). These manipulations are made possible through detailed knowledge of the central dogma process. While this capacity has existed for several decades [34], novel capabilities and genetic tools afforded by synthetic biology may help overcome some of the limitations and time-consuming bottlenecks inherent in established techniques. In this regard, synthetic biology aims to develop foundational technologies such as large-scale, economical de novo DNA synthesis [35] that would increase the efficiency of traditional recombinant DNA technology and genetic engineering. Collectively, synthetic engineering of the central dogma aims to optimize and expand the capabilities of native cellular machinery. The methods and technologies 
developed from this research will contribute to a more powerful and efficient toolbox for the microbial engineer. In this section, we will review synthetic biology technologies and applications for influencing components within the first tier.

2.1. Engineering DNA. DNA manipulation began very early in the biotechnological revolution with recombinant DNA methods [36-38] and DNA sequencing technology [3941]. Mutagenesis techniques and the establishment of standardized molecular biology methods [34] expanded these tools and empowered metabolic engineers with more powerful approaches to improve metabolic phenotypes [42-46]. Despite being straightforward and robust, these approaches are inherently limited by template-based DNA synthesis and restriction enzyme cloning. However, inexpensive, large scale synthetic (de novo) DNA manufacturing technology has the potential to revolutionize this process once again. Unlike traditional methods, de novo synthesis removes the need to engineer cellular systems using preexisting DNA as a template. In this regard, this technology brings about a new power to synthetically design genes, control elements, and circuits that do not exist in nature-thus creating novel function from the basic building blocks of nucleic acids and amino acids.

Already, there are multiple companies with expertise in synthesizing DNA (Blue Heron, DNA2.0, GENEART, IDT, etc.), from small fragments to whole genes and genetic elements. Moreover, improvements and new technologies are continually being published $[12,35,47-50]$ which expand the potential applications and drive down prices. As a result, synthesis capabilities have moved beyond the scale of single genes and into the scale of chemically synthesized genomes $[11,13]$. Moreover, efforts are being made to introduce this synthetic DNA into a generic host [51] in an effort to completely reprogram a cell. The combination of these powerful new DNA synthesis techniques coupled with lowcost DNA sequencing has the potential to confer a great deal of freedom to researchers. With these advances, DNA design and cloning is no longer limited by existing fragments of template DNA and available restriction sites in plasmids. In essence, this technology serves as the basis for other synthetic biology tools, since DNA is the vehicle of almost every biological perturbation, regardless of the tier of interest.

However, our ability to create DNA de novo is not equally matched by a capacity to predict the ideal DNA sequence $a$ priori for a given application. Attempts have been made to catalogue DNA elements $[52,53]$ and predict the function of synthetic networks using models $[9,15,17,18,54]$. Nevertheless, our knowledge base for constructing predictive models of global cellular behavior is limited as is our ability to design large operons and circuits de novo. Future work on characterizing these elements as well as their dynamics and interaction will allow for synthetically created customdesigned genetic circuits.

Simply synthesizing and importing designed DNA is not enough to ensure desired function. Specifically, for these elements to operate efficiently, synthetic DNA operons must act independently and not be negatively influenced by other cellular processes. One solution to mitigate this problem embodies another area of synthetic DNA engineering research: the quest for a minimal cell [55-57]. A minimal cell only contains the essential genetic information required to maintain viability under controlled conditions. In following with the industrial process analogy, this would correspond to a factory containing only the equipment necessary for a given process application. It is clear that this minimization makes sense in a process plant as superfluous equipment would be a waste of precious resources such as money and space. However, cells contain many more parts than are necessary for a given biotechnological application. Thus, taking a cell "off the shelf" can result in limited efficiency. The search for a minimal cell provides a noninterfering "chassis" suitable for manipulation by the biological engineer. Recent advances in cataloging essential genes continue to move the minimal cell closer to reality $[58,59]$. However, it is currently unclear whether the genetic definition of a minimal cell will be generic or process specific. Thus, there may be a suite of minimal cells required; each one suited for different classes of bioproducts.

Another area of synthetic DNA engineering aims to expand the basic genetic code by adding synthetic base pairs [60-63]. Incorporating synthetic codons provides a means of utilizing nonnatural amino acids (see Section 2.3) and introducing nonnative DNA-protein binding pairs. Already, alternative genetic codes have led to new applications for engineered biology [61]. One of the potential difficulties of incorporating synthetic base pairs into DNA is that the threedimensional structure of the molecule may change and key binding proteins and polymerases may not be able to recognize the new genetic language. However, initial results are promising $[63,64]$ and suggest that drastic changes to innate cellular architecture are not required. Thus, alternative base pairs provide a newfound flexibility in genetic code and DNA manipulation technology. Furthermore, this approach is an excellent application for de novo DNA synthesis: the coupling of synthetic base pairs with DNA synthesis technology could create a powerful tool for designing synthetic circuits. Regardless of the application, the capacity to engineer DNA using synthetic biology tools provides new access points to the cell unachievable by previous technology.

2.2. Engineering Transcription. Since the central dogma is so highly integrated, DNA-level perturbations can cause significant alterations in downstream process units (Figure 1). As a result, microbial engineers must be able to synthetically optimize each of the process units. The first process unit in the central dogma is transcription. A large number of proteins, small molecules, and even small RNAs can participate in this process step [5]. Nevertheless, the ultimate goal of this process is RNA transcription-converting DNA into an mRNA message. As a result, synthetic control of this process step influences the rate and capacity of mRNA synthesis.

Not surprisingly, the key step of RNA polymerase II binding to a promoter sequence has been targeted by synthetic 
tools, such as promoter engineering, for the purposes of controlling gene expression levels [65-68]. By creating a library of promoter sequence mutants, a graduated expression profile can be developed. This resulting range of expression affords a more detailed investigation of expression levels beyond traditional wild type-knockout-strong overexpression studies. Furthermore, well-characterized promoters enable more precise gene delivery [52]. A similar requirement for controlled expression is critical for genetic circuits where protein expression must be balanced to maintain a desired steady state. Often these circuits use inducible promoters, and a similar approach can be used to augment the expression capacity of inducible promoters. Thus, welldocumented genetic elements will be extremely useful in creating synthetic cells and circuits. However, transcription is a two-body problem requiring both proteins and DNA. Most previous work focused on the DNA aspect of the problem; however, proteins involved in transcription can also be engineered to synthetically control a cell [32]. Moreover, altering the DNA sequence focuses the change to one particular genetic locus, whereas changing the involved proteins has a profound, global impact.

It is often necessary to alter the transcriptional profile of many genes simultaneously to obtain a desired complex phenotype. This level of synthetic control in the cell is essential for rewiring cells into biofactories. In this regard, another synthetic biology tool termed global transcription machinery engineering (gTME) [30, 69, 70] aims to alter the proteins responsible for the process step of transcription in an effort to exert a pleiotropic downstream effect. The gTME approach operates by creating a mutant library of proteins responsible for transcription (such as sigma factors and TATA binding proteins) and subjecting the library to a high-throughput phenotype screen. This technique is useful for a phenotype that is typically under the control of a multitude of genes. This approach of synthetically rewiring cells at the transcriptional level provides a means of creating large changes within the transcriptome and provides a novel approach to modulating the process step of transcription.

The rationale behind gTME was recently applied to the RNA polymerase II protein itself [32]. By creating a mutant library of the polymerase $\alpha$ subunit and applying selective pressures, the authors demonstrated increases in the tolerance of E. coli to 1-butanol. More studies such as these are required not only to optimize the transcription process unit for synthetic biology applications, but also to gain more fundamental knowledge of the process unit. With enough information, rational design of synthetic transcriptional machinery may be possible. However, largelibrary based selection techniques are currently required to identify promising mutants, limiting the capacity to design transcription machinery de novo.

Also of note for future synthetic biology tool development is reverse transcription, illustrated by the doublepointed arrows in Figure 1. Reverse transcription as a method of gene delivery for disease treatment [71, 72] merits further exploration by synthetic biologists, although this type of work is generally outside the focus of microbial synthetic biologists. Yet, a great deal of work still remains prior to gaining full, synthetic control of the transcription process. Specifically, more studies focusing on the complex interactions between participatory molecules must be performed. These studies will also implicate future molecular targets for strategies similar to promoter engineering and gTME.

\subsection{Engineering Translation. The second major process unit} in the central dogma, translation, has also been the subject of recent synthetic biology research. Similar to transcription, translation encompasses many different classes of molecules that can serve as good targets for optimization and rewiring cells. However, less is known about the most essential molecules in this process.

One of the most successful examples of synthetically engineering translation machinery involves the incorporation of unnatural amino acids into proteins [73]. In this work, mutant aminoacyl tRNA synthetases incorporate amino acids with diverse R-group chemistries into proteins. This approach holds a great deal of promise for the synthetic biologist as a means of creating wholly new biological functions and chemistries [29, 74-76]. This direction towards designer proteins is akin to nontemplate based DNA synthesis. However, as with de novo DNA synthesis, it is not always clear which amino acid(s) should be changed to an unnatural analog to confer a desired protein function of interest. In this regard, more work is required to develop a computational linkage between sequence and function. Nevertheless, this approach gives significant leverage to synthetic biologists to create custom proteins with desired functions.

Another example of engineering translation is gene codon optimization [33]. Codon optimization is a method to bias the redundant codons for each amino acid toward the codons most commonly found in the host organism. This approach is greatly expedited by sequencing and synthesis technologies that can produce the required alternately coded genes. Codon optimization has been shown to be successful in many cases [77-82] and has led to improved translation rates, protein yields, and enzymatic activities. When combined with pathway engineering, codon-optimized pathways are typically more efficient than their unengineered counterpart. This approach is especially important when attempting to produce natural products found in systems distantly related to the host organisms (such as importing plant genes into E. coli [83]). Finally, computational techniques are continually being developed to perform the task of codon optimization and assembly design which will improve our ability to control this process step [84]. However, recent evidence has shown that codon optimization may be more effective due to changes in mRNA secondary structure, as opposed to making more abundant tRNA available for translation [85]. Engineering mRNA secondary structure is a second-tier, regulatory method of controlling the central dogma, and is discussed in that section. With these emerging questions, it remains to be seen if the combination of de novo DNA synthesis with codon optimization algorithms will greatly expedite this process and remove some translation-level limitations in cellular systems. 
2.4. Engineering the First Tier-Summary. The techniques and approaches described above focus on a synthetic approach aimed to redesign the information and process flow in the central dogma. As Figure 1 suggests, manipulation of the central dogma process at any one of the nodes often results in changes at the protein level. As the major catalytic, structural, and signaling components of cells, synthetically modifying proteins is one of the primary goals of engineering biology. Some of these manipulations, such as promoter engineering and codon optimization, are designed to alter protein level, while others, such as directed evolution $[25,86,87]$ and unnatural amino acids, are intended to synthetically alter protein function directly. In either case, the change must be made at the first tier in order to create the downstream effect.

The tools of synthetic biology in this arena have improved the rate and precision of changes that can be made to this first tier. Moreover, they open the capacity to design novel elements and process units that serve a higher biotechnological goal. Yet, more work is required to enable full de novo design of these custom-made elements. In addition, the complete rewiring of cells will likely require multiple modifications in the first tier, thus these approaches must be used in combination to obtain the best results for bioprocessing applications.

\section{The Second Tier-Engineering Process Controls}

A myriad of control systems have evolved to regulate the highly complex process steps of the central dogma. As a result of tight integration between process and control, it is sometimes difficult to clearly delineate between the biological components of control mechanisms and the central dogma process flow. For this review, we propose that microbial control mechanisms are largely those components that interface with the central dogma process steps, but do not function in a catalytic manner with respect to the process step. Using the process control analogy, these components establish, alter, and regulate the biological "set points." Figure 2 depicts hypothetical control mechanisms within the cell to more clearly delineate between the various tiers of cellular processes. Generally, these control elements form a functional link between the central dogma process (the first tier) and the extrinsic environment (the third tier) and relay control messages into changes in the process units and streams. Actual control mechanisms within the cell are much more complex than this simple depiction, as studies on the RpoS subunit of E. coli RNA polymerase II have shown [88]. To this end, the systems biology approach of surveying global protein-protein interactions is pivotal to understanding these complex mechanisms.

Even without full knowledge of cellular regulatory machinery, synthetic biologists have developed tools that establish desirable synthetic set points for the central dogma process units. These tools are required for the function of genetic circuits and control of metabolic pathways. In

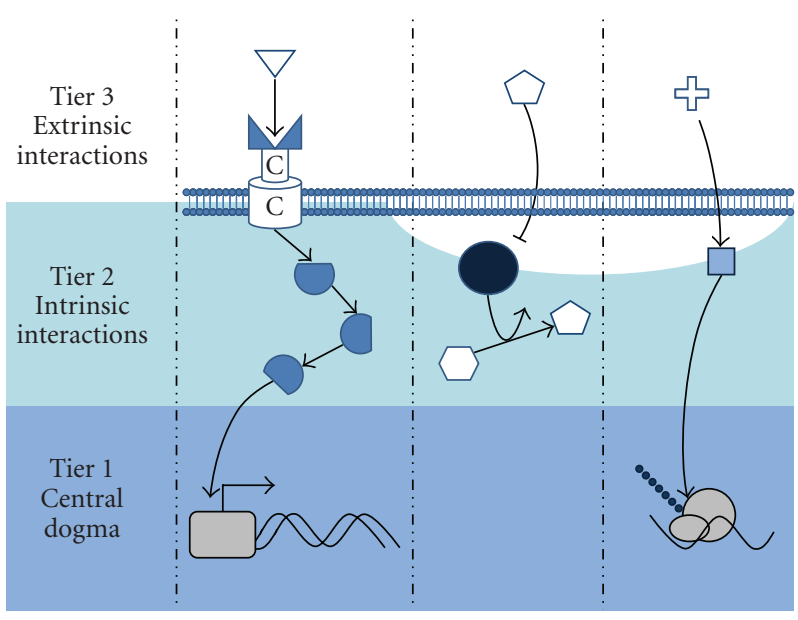

(a)

(b)

(c)

FIGURE 2: Interaction of components illustrating synthetic biology at the three tiers. (a) Canonical signalling pathway depicting a tier three ligand-receptor binding event that induces a tier two phosphorylation cascade which subsequently alters a promoter at the first tier. (b) Canonical allosteric protein inhibition by a molecule downstream in the pathway. The inhibition binding event is a tier three interaction which results in a tier two alteration in the pathway "set point." (c) Hypothetical signalling pathway in which a signal molecule alters an initiation factor at tier three which then changes the tier two protein translation set point.

this section, we will review enabling technologies and applications for synthetic engineering of process control systems within the second tier.

3.1. Transcriptional Control. As stated previously, the control elements involved in many signaling and regulatory networks are being uncovered using a systems biology approach. In particular, these studies are uncovering the important roles that transcription factors play in the process unit of transcription $[7,9,59,89]$. Typically, these interaction networks are reconstructed using high throughput data obtained from two-hybrid, coimmunoprecipitation, or bioinformatic mining protocols. These studies have produced a wealth of data for analysis, although the data is often collected outside of biologically relevant conditions [90]. Recent work is attempting to improve upon these techniques by collecting protein interaction data in native systems with natural protein expression levels [90]. Even with preliminary data and targets, attempts to engineer transcription factor networks have shown promise [31]. If this knowledge gap is closed, imported synthetic circuits and genes could act independently and not be negatively influenced by other cellular processes. Moreover, components of transcription represent a target and provide an access point for synthetic biologists to effect change in biological systems. Therefore, transcriptional control networks should remain an active area of research for synthetic biologists in order to close this knowledge gap and open the possibility for ground-up cellular optimization. 
3.2. Translational Control. In the past few years, a great interest has arisen in the synthetic engineering of RNA $[91,92]$. From a process engineering perspective, RNA serves both as the "feed stream" to the translation process unit and as a central component of the translational machinery itself. Therefore, depending on the application and desired output, engineering of RNA to alter translation can be classified as a first-tier or a second-tier approach to synthetic biology. In terms of translational control, it has been demonstrated that modifying mRNA structure can modulate protein levels $[93,94]$. As an example, by optimizing intergenic regions in an operon [95], hairpins that sequestered ribosomal start codons were introduced and afforded synthetic control of a bicistronic message. Also, similar work has been performed to identify and engineer synthetic ribosome entry (IRES) sites for polycistronic transcripts [96]. Finally, Breaker and colleagues have focused a great deal of effort to the understanding of native RNA response to small molecules [97, 98]. These findings along with research on riboswitches could begin to link translational control with signaling networks or environmental signals (for more on this topic, see Tier 3 ).

Despite these successes, the capacity to engineer translational control mechanisms is quite limited due to the fact that many initiation factors (IF) are yet to be fully characterized and explored. Yet, initial work is beginning to unveil the complex molecular interactions that occur at this level [99101]. However, studies have shown that mRNA levels do not always correlate with protein levels [10, 102]. This disjoint does not reconcile with the simple, reasonable hypothesis embodied by the central dogma that increasing transcript levels should increase protein levels. However, it does provide circumstantial evidence for unknown control mechanisms influencing translation. More studies, perhaps borrowing from the systems biology approach to studying transcription factors $[103,104]$, are required to uncover these translationlevel control mechanisms. If obtained, the full detail of translational control systems will provide a novel means to synthetically control the translation process unit. Therefore, the study of translational control mechanisms should be more fully explored by synthetic biologists.

3.3. Protein Regulation. Regulation occurs at all levels within the cell and is not limited to simply the process units of transcription and translation. In this regard, a great deal of regulation takes place at the protein level, especially upon activity and degradation rate. Also, modifying events such as glycosylation, phosphorylation, and acetylation allow protein function to be modulated and localized within the cell [105-107]. These events regulate cellular activity through activation, inhibition, and signaling. Systems biology is delving into these complex protein-protein interaction networks [108-115]. Supplied with this increasing amount of data, synthetic biologists are constructing synthetic regulatory networks $[116,117]$ that take advantage of these control processes.

As stated previously, protein level within a cell is partially regulated by degradation rates. Synthetic control of these processes is important to (1) aid our understanding of how to extend the half-lives of desirable proteins and (2) further our control of regulatory and signaling systems. To this end, a synthetic protein degradation network has been constructed in Saccharomyces cerevisiae [118]. Eukaryotic systems have elegant processes such as ubiquitination to control degradation, while prokaryotic systems were thought not to possess such capability. However, this has been found to not be the case. Many degradation mechanisms such as the AAA+ protease family in E. coli [119], prokaryotic ubiquitin-like protein (Pup) [120], and others have reversed this thinking. As a result, understanding and engineering protein degradation in prokaryotes can prove to be a fertile area for synthetic biology research in the future.

Protein regulation has been studied since the very beginning of the biotechnological revolution, and is presently becoming influenced by the synthetic biology paradigm. The work previously discussed exemplifies this and opens the door to ground-up cellular optimization.

3.4. Engineering the Second Tier-Summary. The regulatory mechanisms that act upon the central dogma process are vital to optimizing cellular function, from improving product titer to switching gene expression profiles. Synthetic biology has demonstrated that these mechanisms can be effectively engineered at all levels of the central dogma process. By altering regulatory and control systems, it will be possible to ensure that a cell will respond in a desired manner. This is an important trait when considering the behavior of synthetic circuits as well as the function of metabolically engineered organisms. However, more work needs to be done to establish the foundation necessary for ground-up cellular optimization and designer control elements that can leverage these critical regulatory networks.

\section{The Third Tier-Engineering Environmental Signal Reception}

The central dogma and the internal control mechanisms present in the cell have evolved to integrate and respond to a wide array of environmental signals. A short list of stimuli includes temperature, metabolite concentration, light, toxins, ions, and molecular signals from other cells. As we begin to probe cellular systems further, a greater appreciation is being given to cell communication and signaling pathways. New advances in small molecule detection are uncovering key small molecule elicitors. Figure 2, in addition to showing interactions at the second tier, also depicts cellular response to a hypothetical environmental signal at the third tier. This third tier is focused on extracellular molecules and sensing proteins. Once an extracellular molecule interacts with a component of either the internal control mechanisms or of the central dogma, the information has been translated into either the first or second tier. Synthetic engineering of environmental response and communication pathways provides a unique opportunity to exert control in a cellular system. In this section, we will review novel synthetic approaches for signal integration and communication. 
Engineering at this third tier is producing some of the newest work at the frontier of synthetic biology. This area encompasses the work of genetic circuit construction as well as engineering bacterial quorum sensing and microbial consortia [121]. Advancing the toolbox for the microbial engineer at this level is critical for external control of microbial populations. Furthermore, this work provides a newfound method for process control of fermentations. Constructing synthetic sensors that can detect a particular signaling molecule can serve as a responsive switch in a simple genetic circuit as well as a biosensor used to detect toxins in the environment. Furthermore, these systems can be combined to achieve higher logic functions such as AND gates [122]. Engineering at this final tier is the last link in the whole-cell chain of events: environmental signal affects control mechanism, which then elicits change in central dogma, which affects protein levels, and then produces the desired result. As a result, synthetic control of molecular input capability is vital for the complex functions that are currently being designed into microbes.

\subsection{Signal Receptive Genetic Circuits. Modeling biological} networks has borrowed from electrical circuits theory [123], which has given rise to a great deal of analogies between the two fields. The concept of the genetic circuit has become one of the key contributions of synthetic biology $[1,124$, 125]. By definition, genetic circuit design requires an input signal, which represents engineering at the third tier. Due to the many environmental properties a microbe is able to sense, there are a plethora of inputs available to engineer. These inputs can include metabolites [126], proteins [127], temperature [128], and light [129]. Using these inputs, circuits such as switches [127], oscillators [126], bandpass filters [130], and feedback loops [131] may be constructed. Also, it has been shown that genetic circuits can be improved using the directed evolution algorithm typically applied to single proteins [26].

One of the most common positive feedback loops used in genetic circuit engineering is bacterial quorum sensing [132-136]. This natural system of cell-cell communication has been used to initiate cell death for population control, cancer cell invasion [137], artificial predator-prey relationships [138], and cell motility [139]. In these studies, a synthetic quorum sensing response has been introduced into nonnative cells to drive a desired phenotype.

Beyond feedback loops, synthetic biologists could incorporate environmental signals through receptor-ligand interactions [140]. Not surprisingly, protein engineering techniques are important to manipulate these receptor-mediated interactions. Methods such as directed evolution [26, 87, $141]$ are proven, effective methods to accomplishing this end. However, there is also an ongoing push towards rational design of proteins $[142,143]$. As this develops, synthetic biologists will have better avenues towards a priori protein design. Already, there is a great deal of published work on engineering binding pockets of proteins [140] and modeling protein folding changes based on binding events [144]. While these studies had a direct metabolic and medical
[145] application, this approach could contribute to the construction of artificial regulatory networks for proteins that lack native regulation.

In addition, RNA engineering has shown that riboswitches represent a powerful and promising way to incorporate an environmental signal. These small fragments of RNA are a noncoding portion of an mRNA transcript that binds to small molecules, allosterically affecting protein activation levels in the cell $[97,146]$. Moreover, the ability of these fragments to work in an independent fashion allows for a portable, modular assembly of responsive elements [98]. Riboswitches present an exciting new approach to environmental signal recognition because the sequencestructure-function relationship is more predictable than with that of a normal length protein [130]. Success has also been demonstrated designing a riboswitch as a biosensor [147], and constructing artificial switches with natural aptamer domains [148]. There is a great deal more to uncover about the function and applications of riboswitches, and ongoing work in this field will continue in that effort.

4.2. Engineering the Third Tier-Summary. Environmental signal input is essential for programming cellular function. Using the paradigm of genetic circuits, much work has been accomplished to this end. In this regard, the powerful capability of bacterial quorum sensing appears to be a very effective means of synthetically controlling cells. Also, engineering activation and inhibition sites into proteins would allow greater control over biological processes, but work in this area lags due to the unsolved protein sequence-structurefunction problem. A third way to engineer environmental inputs is through riboswitches, an approach that utilizes RNA as the receptor molecule. All of these areas continue to increase the degree to which the central dogma is rationally controlled for specific uses. This capability, coupled with the powerful techniques at the other two tiers, will lead to ground-up engineering of biology.

\section{Integrative Synthetic Biology}

As the development of synthetic biology tools continues to mature, one can envision studies moving towards groundup cellular optimization on a level never before seen. Armed with powerful DNA writing technology, along with the knowledge and ability to manipulate cellular processes, the possibilities for the microbial engineer may become almost limitless. This will be the stage where all of the disparate synthetic biology tools and approaches will be able to be fused with one another, creating the field of integrative synthetic biology.

To date, very few examples of this kind exist since some of the tools and understanding of the parts are lacking. However, recent work from the Keasling laboratory and colleagues provides an initial picture of the type of studies that will be done in this new field. In order to produce the medically valuable product artemisinin, many different approaches have been used, including synthetic pathway construction [83], codon optimization [83], environmental 
signal detection [149], and mRNA secondary structure engineering [95]. Each of these strategies and tools was used in tandem to improve the biotechnological goal, and represent the earliest examples of the power of integrative synthetic biology.

Another example illustrating the reality of integrative synthetic biology is work on orthogonal central dogma machinery. It has already been discussed that the process units of transcription and translation are under a great deal of control, and the mechanisms concerning this control are not yet fully understood. This may overly complicate genetic manipulations, since heterologous gene expression in a host organism is subject to this native central dogma machinery, and the regulatory mechanisms may be unknown or inhibitory. One approach synthetic biologists could use to overcome this difficulty is by designing orthogonal, or noninteracting, transcription and translation machinery [150]. The concept of an orthogonal biological system is an excellent way to avoid undesired host interference, and this has recently been accomplished by combining the specific T7 bacterial promoter system with a previously developed orthogonal ribosome-rRNA pair [151]. This, in effect, creates two AND gates that must be satisfied for heterologous gene expression. Using these types of constructs for engineering control systems and integration of environmental signals may provide the fundamental knowledge needed to understand the more complex and interrelated systems of natural organisms, leading us one step closer to ground-up cellular optimization.

The integrative synthetic biology approach should bring the ability to perform wholesale cellular remodeling into the scope of a single research project. However, as has been iterated at many points in this review, much more basic knowledge and foundational research must be made in order to realize this scenario. In particular, our ability to predict and design components lags behind our ability to engineer them. However, the transformative work that is continually being done in synthetic biology inspires confidence that these techniques may soon be at the fingertips of the microbial engineer.

\section{References}

[1] D. Sprinzak and M. B. Elowitz, "Reconstruction of genetic circuits," Nature, vol. 438, no. 7067, pp. 443-448, 2005.

[2] J.-W. Veening, W. K. Smits, and O. P. Kuipers, "Bistability, epigenetics, and bet-hedging in bacteria," Annual Review of Microbiology, vol. 62, pp. 193-210, 2008.

[3] N. Mitarai, K. Sneppen, and S. Pedersen, "Ribosome collisions and translation efficiency: optimization by codon usage and mRNA destabilization," Journal of Molecular Biology, vol. 382, no. 1, pp. 236-245, 2008.

[4] V. Ramakrishnan, "Ribosome structure and the mechanism of translation," Cell, vol. 108, no. 4, pp. 557-572, 2002.

[5] R. J. Sims III, S. S. Mandal, and D. Reinberg, "Recent highlights of RNA-polymerase-II-mediated transcription," Current Opinion in Cell Biology, vol. 16, no. 3, pp. 263-271, 2004.

[6] P. B. Moore, “The ribosome returned," Journal of Biology, vol. 8 , no. 1 , article $8,2009$.
[7] K. Tan, T. Shlomi, H. Feizi, T. Ideker, and R. Sharan, "Transcriptional regulation of protein complexes within and across species," Proceedings of the National Academy of Sciences of the United States of America, vol. 104, no. 4, pp. 1283-1288, 2007.

[8] A. Roguev, S. Bandyopadhyay, M. Zofall, et al., "Conservation and rewiring of functional modules revealed by an epistasis map in fission yeast," Science, vol. 322, no. 5900, pp. 405-410, 2008.

[9] M. M. Babu, B. Lang, and L. Aravind, "Methods to reconstruct and compare transcriptional regulatory networks," Methods in Molecular Biology, vol. 541, pp. 163-180, 2009.

[10] J. F. Moxley, M. C. Jewett, M. R. Antoniewicz, et al., "Linking high-resolution metabolic flux phenotypes and transcriptional regulation in yeast modulated by the global regulator Gcn4p," Proceedings of the National Academy of Sciences of the United States of America, vol. 106, no. 16, pp. 6477-6482, 2009.

[11] H. O. Smith, C. A. Hutchison III, C. Pfannkoch, and J. C. Venter, "Generating a synthetic genome by whole genome assembly: $\varphi$ X174 bacteriophage from synthetic oligonucleotides," Proceedings of the National Academy of Sciences of the United States of America, vol. 100, no. 26, pp. 15440$15445,2003$.

[12] J. Tian, H. Gang, N. Sheng, et al., "Accurate multiplex gene synthesis from programmable DNA microchips," Nature, vol. 432, no. 7020, pp. 1050-1054, 2004.

[13] D. G. Gibson, G. A. Benders, C. Andrews-Pfannkoch, et al., "Complete chemical synthesis, assembly, and cloning of a Mycoplasma genitalium genome," Science, vol. 319, no. 5867, pp. 1215-1220, 2008.

[14] T. Ideker, V. Thorsson, J. A. Ranish, et al., "Integrated genomic and proteomic analyses of a systematically perturbed metabolic network," Science, vol. 292, no. 5518, pp. 929-934, 2001.

[15] B.-K. Cho, P. Charusanti, M. J. Herrgard, and B. Palsson, "Microbial regulatory and metabolic networks," Current Opinion in Biotechnology, vol. 18, no. 4, pp. 360-364, 2007.

[16] D. Greber and M. Fussenegger, "Mammalian synthetic biology: engineering of sophisticated gene networks," Journal of Biotechnology, vol. 130, no. 4, pp. 329-345, 2007.

[17] S. Noack, A. Wahl, M. Haunschild, E. Qeli, B. Freisleben, and W. Wiechert, "Visualizing regulatory interdependencies and parameter sensitivities in biochemical network models," Mathematics and Computers in Simulation, vol. 79, no. 4, pp. 991-998, 2008.

[18] T. Ellis, X. Wang, and J. J. Collins, "Diversity-based, modelguided construction of synthetic gene networks with predicted functions," Nature Biotechnology, vol. 27, no. 5, pp. 465-471, 2009.

[19] A. Meyer, R. Pellaux, and S. Panke, "Bioengineering novel in vitro metabolic pathways using synthetic biology," Current Opinion in Microbiology, vol. 10, no. 3, pp. 246-253, 2007.

[20] K. E. Tyo, H. S. Alper, and G. N. Stephanopoulos, "Expanding the metabolic engineering toolbox: more options to engineer cells," Trends in Biotechnology, vol. 25, no. 3, pp. 132-137, 2007.

[21] J. D. Keasling, "Synthetic biology for synthetic chemistry," ACS Chemical Biology, vol. 3, no. 1, pp. 64-76, 2008.

[22] S. K. Lee, H. Chou, T. S. Ham, T. S. Lee, and J. D. Keasling, "Metabolic engineering of microorganisms for biofuels production: from bugs to synthetic biology to fuels," Current Opinion in Biotechnology, vol. 19, no. 6, pp. 556-563, 2008. 
[23] K. L. J. Prather and C. H. Martin, "De novo biosynthetic pathways: rational design of microbial chemical factories," Current Opinion in Biotechnology, vol. 19, no. 5, pp. 468-474, 2008.

[24] Z. Shao, H. Zhao, and H. M. Zhao, "DNA assembler, an in vivo genetic method for rapid construction of biochemical pathways," Nucleic Acids Research, vol. 37, no. 2, 2009.

[25] H. Zhao, Y. Li, and F. H. Arnold, "Strategy for the directed evolution of a peptide ligase," Annals of the New York Academy of Sciences, vol. 799, pp. 1-5, 1996.

[26] Y. Yokobayashi, R. Weiss, and F. H. Arnold, "Directed evolution of a genetic circuit," Proceedings of the National Academy of Sciences of the United States of America, vol. 99, no. 26, pp. 16587-16591, 2002.

[27] A. J. Link, M. L. Mock, and D. A. Tirrell, "Non-canonical amino acids in protein engineering," Current Opinion in Biotechnology, vol. 14, no. 6, pp. 603-609, 2003.

[28] H. Bayley and L. Jayasinghe, "Functional engineered channels and pores," Molecular Membrane Biology, vol. 21, no. 4, pp. 209-220, 2004.

[29] J. Xie and P. G. Schultz, "A chemical toolkit for proteinsan expanded genetic code," Nature Reviews Molecular Cell Biology, vol. 7, no. 10, pp. 775-782, 2006.

[30] H. Alper and G. Stephanopoulos, "Global transcription machinery engineering: a new approach for improving cellular phenotype," Metabolic Engineering, vol. 9, no. 3, pp. 258-267, 2007.

[31] T. A. Desai, D. A. Rodionov, M. S. Gelfand, E. J. Alm, and C. V. Rao, "Engineering transcription factors with novel DNAbinding specificity using comparative genomics," Nucleic Acids Research, vol. 37, no. 8, pp. 2493-2503, 2009.

[32] D. Klein-Marcuschamer, C. N. S. Santos, H. Yu, and G. Stephanopoulos, "Mutagenesis of the bacterial RNA polymerase alpha subunit for improvement of complex phenotypes," Applied and Environmental Microbiology, vol. 75, no. 9, pp. 2705-2711, 2009.

[33] B. P. Cormack, G. Bertram, M. Egerton, N. A. R. Gow, S. Falkow, and A. J. P. Brown, "Yeast-enhanced green fluorescent protein (yEGFP): a reporter of gene expression in Candida albicans," Microbiology, vol. 143, no. 2, pp. 303-311, 1997.

[34] J. Sambrook, Molecular Cloning: A Laboratory Manual, edited by D. W. Russell, Cold Spring Harbor Laboratory Press, Cold Spring Harbor, NY, USA, 2000.

[35] J. Tian, K. Ma, and I. Saaem, "Advancing high-throughput gene synthesis technology," Molecular BioSystems, vol. 5, no. 7, pp. 714-722, 2009.

[36] D. V. Goeddel, D. G. Kleid, F. Bolivar, et al., "Expression in Escherichia coli of chemically synthesized genes for human insulin," Proceedings of the National Academy of Sciences of the United States of America, vol. 76, no. 1, pp. 106-110, 1979.

[37] S. Nagata, H. Taira, A. Hall, et al., "Synthesis in Escherichia coli of a polypeptide with human leukocyte interferon activity," Nature, vol. 284, no. 5754, pp. 316-320, 1980.

[38] S. Slater, T. Gallaher, and D. Dennis, "Production of poly(3-hydroxybutyrate-co-3-hydroxyvalerate) in a recombinant Escherichia coli strain," Applied and Environmental Microbiology, vol. 58, no. 4, pp. 1089-1094, 1992.

[39] J. Messing, R. Crea, and P. H. Seeburg, "A system for shotgun DNA sequencing," Nucleic Acids Research, vol. 9, no. 2, pp. 309-321, 1981.
[40] G. M. Church and S. Kieffer-Higgins, "Multiplex DNA sequencing," Science, vol. 240, no. 4849, pp. 185-188, 1988.

[41] F. Sanger, S. Nicklen, and A. R. Coulson, "DNA sequencing with chain-terminating inhibitors," Proceedings of the National Academy of Sciences of the United States of America, vol. 74, no. 12, pp. 5463-5467, 1977.

[42] J. E. Bailey, "Toward a science of metabolic engineering," Science, vol. 252, no. 5013, pp. 1668-1675, 1991.

[43] S.-W. Kim and J. D. Keasling, "Metabolic engineering of the nonmevalonate isopentenyl diphosphate synthesis pathway in Escherichia coli enhances lycopene production," Biotechnology \& Bioengineering, vol. 72, no. 4, pp. 408-415, 2001.

[44] W. Wiechert, "13 C metabolic flux analysis," Metabolic Engineering, vol. 3, no. 3, pp. 195-206, 2001.

[45] H. Alper, Y.-S. Jin, J. F. Moxley, and G. Stephanopoulos, "Identifying gene targets for the metabolic engineering of lycopene biosynthesis in Escherichia coli," Metabolic Engineering, vol. 7, no. 3, pp. 155-164, 2005.

[46] S. Atsumi, A. F. Cann, M. R. Connor, et al., "Metabolic engineering of Escherichia coli for 1-butanol production," Metabolic Engineering, vol. 10, no. 6, pp. 305-311, 2008.

[47] G. Linshiz, T. B. Yehezkel, S. Kaplan, et al., "Recursive construction of perfect DNA molecules from imperfect oligonucleotides," Molecular Systems Biology, vol. 4, 2008.

[48] D. Bang and G. M. Church, "Gene synthesis by circular assembly amplification," Nature Methods, vol. 5, no. 1, pp. 37-39, 2008.

[49] H. Ye, M. C. Huang, M.-H. Li, and J. Y. Ying, "Experimental analysis of gene assembly with TopDown one-step real-time gene synthesis," Nucleic Acids Research, vol. 37, no. 7, p. e51, 2009.

[50] S. Blair, K. Richmond, M. Rodesch, M. Bassetti, and F. Cerrina, "A scalable method for multiplex LED-controlled synthesis of DNA in capillaries," Nucleic Acids Research, vol. 34, no. 16, 2006.

[51] C. Lartigue, J. I. Glass, N. Alperovich, et al., "Genome transplantation in bacteria: changing one species to another," Science, vol. 317, no. 5838, pp. 632-638, 2007.

[52] J. R. Kelly, A. J. Rubin, J. H. Davis, et al., "Measuring the activity of BioBrick promoters using an in vivo reference standard," Journal of Biological Engineering, vol. 3, article 4, 2009.

[53] R. P. Shetty, D. Endy, and T. F. Knight Jr., "Engineering BioBrick vectors from BioBrick parts," Journal of Biological Engineering, vol. 2, article 5, 2008.

[54] L. M. Tran, M. L. Rizk, and J. C. Liao, "Ensemble modeling of metabolic networks," Biophysical Journal, vol. 95, no. 12, pp. 5606-5617, 2008.

[55] J. Carrera, G. Rodrigo, and A. Jaramillo, "Model-based redesign of global transcription regulation," Nucleic Acids Research, vol. 37, no. 5, 2009.

[56] A. C. Forster and G. M. Church, "Towards synthesis of a minimal cell," Molecular Systems Biology, vol. 2, article 45, 2006.

[57] A. Moya, R. Gil, A. Latorre, J. Pereto, M. P. Garcillan-Barcia, and F. de La Cruz, "Toward minimal bacterial cells: evolution vs. design," FEMS Microbiology Reviews, vol. 33, no. 1, pp. 225-235, 2009.

[58] J. I. Glass, N. Assad-Garcia, N. Alperovich, et al., "Essential genes of a minimal bacterium," Proceedings of the National Academy of Sciences of the United States of America, vol. 103, no. 2, pp. 425-430, 2006. 
[59] R. Zhang and Y. Lin, "DEG 5.0, a database of essential genes in both prokaryotes and eukaryotes," Nucleic Acids Research, vol. 37, supplement 1, pp. D455-D458, 2009.

[60] C. Switzer, S. E. Moroney, and S. A. Benner, "Enzymatic incorporation of a new base pair into DNA and RNA," Journal of the American Chemical Society, vol. 111, no. 21, pp. 8322-8323, 1989.

[61] S. A. Benner and A. M. Sismour, "Synthetic biology," Nature Reviews Genetics, vol. 6, no. 7, pp. 533-543, 2005.

[62] Z. Y. Yang, D. Hutter, P. Sheng, A. M. Sismour, and S. A. Benner, "Artificially expanded genetic information system: a new base pair with an alternative hydrogen bonding pattern," Nucleic Acids Research, vol. 34, no. 21, pp. 6095-6101, 2006.

[63] S. A. Havemann, S. Hoshika, D. Hutter, and S. A. Benner, "Incorporation of multiple sequential pseudothymidines by DNA polymerases and their impact on DNA duplex structure," Nucleosides, Nucleotides \& Nucleic Acids, vol. 27, no. 3, pp. 261-278, 2008.

[64] Z. Y. Yang, A. M. Sismour, P. Sheng, N. L. Puskar, and S. A. Benner, "Enzymatic incorporation of a third nucleobase pair," Nucleic Acids Research, vol. 35, no. 13, pp. 4238-4249, 2007.

[65] P. R. Jensen and K. Hammer, "The sequence of spacers between the consensus sequences modulates the strength of prokaryotic promoters," Applied and Environmental Microbiology, vol. 64, no. 1, pp. 82-87, 1998.

[66] H. Alper, C. Fischer, E. Nevoigt, and G. Stephanopoulos, "Tuning genetic control through promoter engineering," Proceedings of the National Academy of Sciences of the United States of America, vol. 102, no. 36, pp. 12678-12683, 2005.

[67] M. Venter, "Synthetic promoters: genetic control through cis engineering," Trends in Plant Science, vol. 12, no. 3, pp. 118124, 2007.

[68] F. S. Hartner, C. Ruth, D. Langenegger, et al., "Promoter library designed for fine-tuned gene expression in Pichia pastoris," Nucleic Acids Research, vol. 36, no. 12, 2008.

[69] H. Yu, K. Tyo, H. Alper, D. Klein-Marcuschamer, and G. Stephanopoulos, "A high-throughput screen for hyaluronic acid accumulation in recombinant Escherichia coli transformed by libraries of engineered sigma factors," Biotechnology \& Bioengineering, vol. 101, no. 4, pp. 788-796, 2008.

[70] H. Liu, M. Yan, C. Lai, L. Xu, and P. Ouyang, "gTME for improved Xylose fermentation of Saccharomyces cerevisiae," to appear in Applied Biochemistry and Biotechnology.

[71] D. V. Schaffer, J. T. Koerber, and K.-I. Lim, "Molecular engineering of viral gene delivery vehicles," Annual Review of Biomedical Engineering, vol. 10, pp. 169-194, 2008.

[72] R. Alemany, C. Balague, and D. T. Curiel, "Replicative adenoviruses for cancer therapy," Nature Biotechnology, vol. 18, no. 7, pp. 723-727, 2000.

[73] C. J. Noren, S. J. Anthony-Cahill, M. C. Griffith, and P. G. Schultz, "A general method for site-specific incorporation of unnatural amino acids into proteins," Science, vol. 244, no. 4901, pp. 182-188, 1989.

[74] K. C. Schultz, L. Supekova, Y. Ryu, J. Xie, R. Perera, and P. G. Schultz, "A genetically encoded infrared probe," Journal of the American Chemical Society, vol. 128, no. 43, pp. 1398413985, 2006.

[75] C. C. Liu, A. V. Mack, M.-L. Tsao, et al., "Protein evolution with an expanded genetic code," Proceedings of the National Academy of Sciences of the United States of America, vol. 105, no. 46, pp. 17688-17693, 2008.
[76] H. S. Lee, G. Spraggon, P. G. Schultz, and F. Wang, "Genetic incorporation of a metal-ion chelating amino acid into proteins as a biophysical probe," Journal of the American Chemical Society, vol. 131, no. 7, pp. 2481-2483, 2009.

[77] N. A. Burgess-Brown, S. Sharma, F. Sobott, C. Loenarz, U. Oppermann, and O. Gileadi, "Codon optimization can improve expression of human genes in Escherichia coli: a multi-gene study," Protein Expression and Purification, vol. 59, no. 1, pp. 94-102, 2008.

[78] H. Foster, P. S. Sharp, T. Athanasopoulos, et al., "Codon and mRNA sequence optimization of microdystrophin transgenes improves expression and physiological outcome in dystrophic mdx mice following AAV2/8 gene transfer," Molecular Therapy, vol. 16, no. 11, pp. 1825-1832, 2008.

[79] S. Sasaguri, J.-I. Maruyama, S. Moriya, T. Kudo, K. Kitamoto, and M. Arioka, "Codon optimization prevents premature polyadenylation of heterologously-expressed cellulases from termite-gut symbionts in Aspergllus oryzae," Journal of General and Applied Microbiology, vol. 54, no. 6, pp. 343-351, 2008.

[80] M. Tokuoka, M. Tanaka, K. Ono, S. Takagi, T. Shintani, and K. Gomi, "Codon optimization increases steady-state mRNA levels in Aspergillus oryzae heterologous gene expression," Applied and Environmental Microbiology, vol. 74, no. 21, pp. 6538-6546, 2008.

[81] H. Wang, Q. Wang, F. Zhang, Y. Huang, Y. Ji, and Y. Hou, "Protein expression and purification of human Zbtb7A in Pichia pastoris via gene codon optimization and synthesis," Protein Expression and Purification, vol. 60, no. 2, pp. 97-102, 2008.

[82] Z.-L. Wu, J. Qiao, Z.-G. Zhang, F. P. Guengerich, Y. Liu, and X.-Q. Pei, "Enhanced bacterial expression of several mammalian cytochrome P450s by codon optimization and chaperone coexpression," Biotechnology Letters, vol. 31, no. 10, pp. 1589-1593, 2009.

[83] V. J. J. Martin, D. J. Piteral, S. T. Withers, J. D. Newman, and J. D. Keasling, "Engineering a mevalonate pathway in Escherichia coli for production of terpenoids," Nature Biotechnology, vol. 21, no. 7, pp. 796-802, 2003.

[84] K. S. Sandhu, S. Pandey, S. Maiti, and B. Pillai, "GASCO: genetic algorithm simulation for codon optimization," In Silico Biology, vol. 8, no. 2, pp. 187-192, 2008.

[85] G. Kudla, A. W. Murray, D. Tollervey, and J. B. Plotkin, "Coding-sequence determinants of expression in Escherichia coli," Science, vol. 324, no. 5924, pp. 255-258, 2009.

[86] J. C. Moore and F. H. Arnold, "Directed evolution of a paranitrobenzyl esterase for aqueous-organic solvents," Nature Biotechnology, vol. 14, no. 4, pp. 458-467, 1996.

[87] L. You and F. H. Arnold, "Directed evolution of subtilisin $\mathrm{E}$ in Bacillus subtilis to enhance total activity in aqueous dimethylformamide," Protein Engineering, vol. 9, no. 1, pp. 77-83, 1996.

[88] R. Hengge-Aronis, "Signal transduction and regulatory mechanisms involved in control of the $\sigma^{s}$ (RpoS) subunit of RNA polymerase," Microbiology and Molecular Biology Reviews, vol. 66, no. 3, pp. 373-395, 2002.

[89] E. Balleza, L. N. López-Bojorquez, A. Martínez-Antonio, et al., "Regulation by transcription factors in bacteria: beyond description," FEMS Microbiology Reviews, vol. 33, no. 1, pp. 133-151, 2009.

[90] J. Muller and N. Johnsson, "Split-ubiquitin and the splitprotein sensors: chessman for the endgame," ChemBioChem, vol. 9, no. 13, pp. 2029-2038, 2008. 
[91] F. J. Isaacs, D. J. Dwyer, and J. J. Collins, "RNA synthetic biology," Nature Biotechnology, vol. 24, no. 5, pp. 545-554, 2006.

[92] M. N. Win, J. C. Liang, and C. D. Smolke, "Frameworks for programming biological function through RNA parts and devices," Chemistry \& Biology, vol. 16, no. 3, pp. 298-310, 2009.

[93] C. D. Smolke, T. A. Carrier, and J. D. Keasling, "Coordinated, differential expression of two genes through directed mRNA cleavage and stabilization by secondary structures," Applied and Environmental Microbiology, vol. 66, no. 12, pp. 53995405, 2000.

[94] C. D. Smolke, V. J. J. Martin, and J. D. Keasling, "Controlling the metabolic flux through the carotenoid pathway using directed mRNA processing and stabilization," Metabolic Engineering, vol. 3, no. 4, pp. 313-321, 2001.

[95] B. F. Pfleger, D. J. Pitera, C. D. Smolke, and J. D. Keasling, "Combinatorial engineering of intergenic regions in operons tunes expression of multiple genes," Nature Biotechnology, vol. 24, no. 8, pp. 1027-1032, 2006.

[96] A. Venkatesan and A. Dasgupta, "Novel fluorescence-based screen to identify small synthetic internal ribosome entry site elements," Molecular and Cellular Biology, vol. 21, no. 8, pp. 2826-2837, 2001.

[97] M. Mandal and R. R. Breaker, "Gene regulation by riboswitches," Nature Reviews Molecular Cell Biology, vol. 5, no. 6, pp. 451-463, 2004.

[98] J. N. Kim, K. F. Blount, J. Lim, K. H. Link, and R. Breaker, "Design and antimicrobial action of purine analogues that bind Guanine riboswitches," ACS Chemical Biology, vol. 4, no. 11, pp. 915-927, 2009.

[99] A.-C. Gingras, B. Raught, and N. Sonenberg, "eIF4 initiation factors: effectors of mRNA recruitment to ribosomes and regulators of translation," Annual Review of Biochemistry, vol. 68, pp. 913-963, 1999.

[100] A. Pacheco, S. L. de Quinto, J. Ramajo, N. Fernandez, and E. Martinez-Salas, "A novel role for Gemin5 in mRNA translation," Nucleic Acids Research, vol. 37, no. 2, pp. 582590, 2009.

[101] P. Saini, D. E. Eyler, R. Green, and T. E. Dever, "Hypusinecontaining protein eIF5A promotes translation elongation," Nature, vol. 459, no. 7243, pp. 118-121, 2009.

[102] T. J. Griffin, S. P. Gygi, T. Ideker, et al., "Complementary profiling of gene expression at the transcriptome and proteome levels in Saccharomyces cerevisiae," Molecular \& Cellular Proteomics, vol. 1, no. 4, pp. 323-333, 2002.

[103] A. Subramanian, P. Tamayo, V. K. Mootha, et al., "Gene set enrichment analysis: a knowledge-based approach for interpreting genome-wide expression profiles," Proceedings of the National Academy of Sciences of the United States of America, vol. 102, no. 43, pp. 15545-15550, 2005.

[104] L. M. Tran, M. P. Brynildsen, K. C. Kao, J. K. Suen, and J. C. Liao, "gNCA: a framework for determining transcription factor activity based on transcriptome: identifiability and numerical implementation," Metabolic Engineering, vol. 7, no. 2, pp. 128-141, 2005.

[105] C. L. Brooks and W. Gu, "Ubiquitination, phosphorylation and acetylation: the molecular basis for p53 regulation," Current Opinion in Cell Biology, vol. 15, no. 2, pp. 164-171, 2003.

[106] J. Seo and K.-J. Lee, "Post-translational modifications and their biological functions: proteomic analysis and systematic approaches," Journal of Biochemistry and Molecular Biology, vol. 37, no. 1, pp. 35-44, 2004.
[107] M. Mann and O. N. Jensen, "Proteomic analysis of posttranslational modifications," Nature Biotechnology, vol. 21, no. 3, pp. 255-261, 2003.

[108] N. J. Krogan, G. Cagney, H. Yu, et al., "Global landscape of protein complexes in the yeast Saccharomyces cerevisiae," Nature, vol. 440, no. 7084, pp. 637-643, 2006.

[109] P. Shannon, A. Markiel, O. Ozier, et al., "Cytoscape: a software environment for integrated models of biomolecular interaction networks," Genome Research, vol. 13, no. 11, pp. 2498-2504, 2003.

[110] I. Xenarios, Ł. Salwínski, X. J. Duan, P. Higney, S.-M. Kim, and D. Eisenberg, "DIP, the database of interacting proteins: a research tool for studying cellular networks of protein interactions," Nucleic Acids Research, vol. 30, no. 1, pp. 303305, 2002.

[111] Y. Ho, A. Gruhler, A. Heilbut, et al., "Systematic identification of protein complexes in Saccharomyces cerevisiae by mass spectrometry," Nature, vol. 415, no. 6868, pp. 180-183, 2002.

[112] M. Mann, R. C. Hendrickson, and A. Pandey, "Analysis of proteins and proteomes by mass spectrometry," Annual Review of Biochemistry, vol. 70, pp. 437-473, 2001.

[113] T. Ito, T. Chiba, R. Ozawa, M. Yoshida, M. Hattori, and Y. Sakaki, "A comprehensive two-hybrid analysis to explore the yeast protein interactome," Proceedings of the National Academy of Sciences of the United States of America, vol. 98, no. 8, pp. 4569-4574, 2001.

[114] T. Ito, K. Tashiro, S. Muta, et al., “Toward a protein-protein interaction map of the budding yeast: a comprehensive system to examine two-hybrid interactions in all possible combinations between the yeast proteins," Proceedings of the National Academy of Sciences of the United States of America, vol. 97, no. 3, pp. 1143-1147, 2000.

[115] S. Fields and R. Sternglanz, "The two-hybrid system: an assay for protein-protein interactions," Trends in Genetics, vol. 10, no. 8, pp. 286-292, 1994.

[116] P. M. Pryciak, "Designing new cellular signaling pathways," Chemistry \& Biology, vol. 16, no. 3, pp. 249-254, 2009.

[117] R. P. Bhattacharyya, A. Remenyi, B. J. Yeh, and W. A. Lim, "Domains, motifs, and scaffolds: the role of modular interactions in the evolution and wiring of cell signaling circuits," Annual Review of Biochemistry, vol. 75, pp. 655-680, 2006.

[118] C. Grilly, J. Stricker, W. L. Pang, M. R. Bennett, and J. Hasty, "A synthetic gene network for tuning protein degradation in Saccharomyces cerevisiae," Molecular Systems Biology, vol. 3, article 127, 2007.

[119] S. Gottesman, E. Roche, Y. N. Zhou, and R. T. Sauer, "The ClpXP and ClpAP proteases degrade proteins with carboxyterminal peptide tails added by the SsrA-tagging system," Genes \& Development, vol. 12, no. 9, pp. 1338-1347, 1998.

[120] K. H. Darwin, "Prokaryotic ubiquitin-like protein (Pup), proteasomes and pathogenesis," Nature Reviews Microbiology, vol. 7, no. 7, pp. 485-491, 2009.

[121] K. Brenner, L. You, and F. H. Arnold, "Engineering microbial consortia: a new frontier in synthetic biology," Trends in Biotechnology, vol. 26, no. 9, pp. 483-489, 2008.

[122] J. C. Anderson, C. A. Voigt, and A. P. Arkin, "Environmental signal integration by a modular and gate," Molecular Systems Biology, vol. 3, article 133, 2007.

[123] H. H. McAdams and L. Shapiro, "Circuit simulation of genetic networks,” Science, vol. 269, no. 5224, pp. 650-656, 1995. 
[124] D. J. Sayut, P. K. R. Kambam, and L. Sun, "Engineering and applications of genetic circuits," Molecular BioSystems, vol. 3, no. 12, pp. 835-840, 2007.

[125] K. Michalodimitrakis and M. Isalan, "Engineering prokaryotic gene circuits," FEMS Microbiology Reviews, vol. 33, no. 1, pp. 27-37, 2009.

[126] E. Fung, W. W. Wong, J. K. Suen, T. Bulter, S. G. Lee, and J. C. Liao, "A synthetic gene-metabolic oscillator," Nature, vol. 435, no. 7038, pp. 118-122, 2005.

[127] W. Weber, C. Lienhart, D. M. El Baba, and M. Fussenegger, "A biotin-triggered genetic switch in mammalian cells and mice," Metabolic Engineering, vol. 11, no. 2, pp. 117-124, 2009.

[128] T. Waldminghaus, J. Kortmann, S. Gesing, and F. Narberhaus, "Generation of synthetic RNA-based thermosensors," Biological Chemistry, vol. 389, no. 10, pp. 1319-1326, 2008.

[129] A. Levskaya, A. A. Chevalier, J. J. Tabor, et al., "Synthetic biology: engineering Escherichia coli to see light," Nature, vol. 438, no. 7067, pp. 441-442, 2005.

[130] T. Sohka, R. A. Heins, R. M. Phelan, J. M. Greisler, C. A. Townsend, and M. Ostermeier, "An externally tunable bacterial band-pass filter," Proceedings of the National Academy of Sciences of the United States of America, vol. 106, no. 25, pp. 10135-10140, 2009.

[131] T. Kobayashi, L. Chen, and K. Aihara, "Modeling genetic switches with positive feedback loops," Journal of Theoretical Biology, vol. 221, no. 3, pp. 379-399, 2003.

[132] M. B. Miller and B. L. Bassler, "Quorum sensing in bacteria," Annual Review of Microbiology, vol. 55, pp. 165-199, 2001.

[133] W. C. Fuqua, S. C. Winans, and E. P. Greenberg, "Quorum sensing in bacteria: the LuxR-LuxI family of cell densityresponsive transcriptional regulators," Journal of Bacteriology, vol. 176, no. 2, pp. 269-275, 1994.

[134] E. L. Haseltine and F. H. Arnold, "Implications of rewiring bacterial quorum sensing," Applied and Environmental Microbiology, vol. 74, no. 2, pp. 437-445, 2008.

[135] S. Hooshangi and W. E. Bentley, "From unicellular properties to multicellular behavior: bacteria quorum sensing circuitry and applications," Current Opinion in Biotechnology, vol. 19, no. 6, pp. 550-555, 2008.

[136] L. You, R. S. Cox III, R. Weiss, and F. H. Arnold, "Programmed population control by cell-cell communication and regulated killing," Nature, vol. 428, no. 6985, pp. 868871, 2004.

[137] J. C. Anderson, E. J. Clarke, A. P. Arkin, and C. A. Voigt, "Environmentally controlled invasion of cancer cells by engineered bacteria," Journal of Molecular Biology, vol. 355, no. 4, pp. 619-627, 2006.

[138] F. K. Balagadde, H. Song, J. Ozaki, et al., "A synthetic Escherichia coli predator-prey ecosystem," Molecular Systems Biology, vol. 4, article 187, 2008.

[139] L. E. Weiss, J. P. Badalamenti, L. J. Weaver, et al., "Engineering motility as a phenotypic response to LuxI/R-dependent quorum sensing in Escherichia coli," Biotechnology \& Bioengineering, vol. 100, no. 6, pp. 1251-1255, 2008.

[140] J. T. Koh, "Engineering selectivity and discrimination into ligand-receptor interfaces," Chemistry \& Biology, vol. 9, no. 1, pp. 17-23, 2002.

[141] Z. Shao and F. H. Arnold, "Engineering new functions and altering existing functions," Current Opinion in Structural Biology, vol. 6, no. 4, pp. 513-518, 1996.
[142] L. Jiang, E. A. Althoff, F. R. Clemente, et al., "De novo computational design of retro-aldol enzymes," Science, vol. 319, no. 5868, pp. 1387-1391, 2008.

[143] D. Rothlisberger, O. Khersonsky, A. M. Wollacott, et al., "Kemp elimination catalysts by computational enzyme design," Nature, vol. 453, no. 7192, pp. 190-195, 2008.

[144] B. K. Ho and D. A. Agard, "Probing the flexibility of large conformational changes in protein structures through local perturbations," PLoS Computational Biology, vol. 5, article 4, 2009.

[145] N. V. Wase and P. C. Wright, "Systems biology of cyanobacterial secondary metabolite production and its role in drug discovery," Expert Opinion on Drug Discovery, vol. 3, no. 8, pp. 903-929, 2008.

[146] A. Roth and R. R. Breaker, "The structural and functional diversity of metabolite-binding riboswitches," Annual Review of Biochemistry, vol. 78, pp. 305-334, 2009.

[147] N. Muranaka, V. Sharma, Y. Nomura, and Y. Yokobayashi, "Efficient design strategy for whole-cell and cell-free biosensors based on engineered riboswitches," Analytical Letters, vol. 42, no. 1, pp. 108-122, 2009.

[148] M. Wieland, A. Benz, B. Klauser, and J. S. Hartig, "Artificial ribozyme switches containing natural riboswiteh aptamer domains," Angewandte Chemie, vol. 48, no. 15, pp. 27152718, 2009.

[149] B. F. Pfleger, D. J. Pitera, J. D. Newman, V. J. J. Martin, and J. D. Keasling, "Microbial sensors for small molecules: development of a mevalonate biosensor," Metabolic Engineering, vol. 9, no. 1, pp. 30-38, 2007.

[150] O. Rackham and J. W. Chin, Synthesizing Cellular Networks from Evolved Ribosome-mRNA Pairs, Portland Press, London, UK, 2006.

[151] W. An and J. W. Chin, "Synthesis of orthogonal transcription-translation networks," Proceedings of the National Academy of Sciences of the United States of America, vol. 106, no. 21, pp. 8477-8482, 2009. 

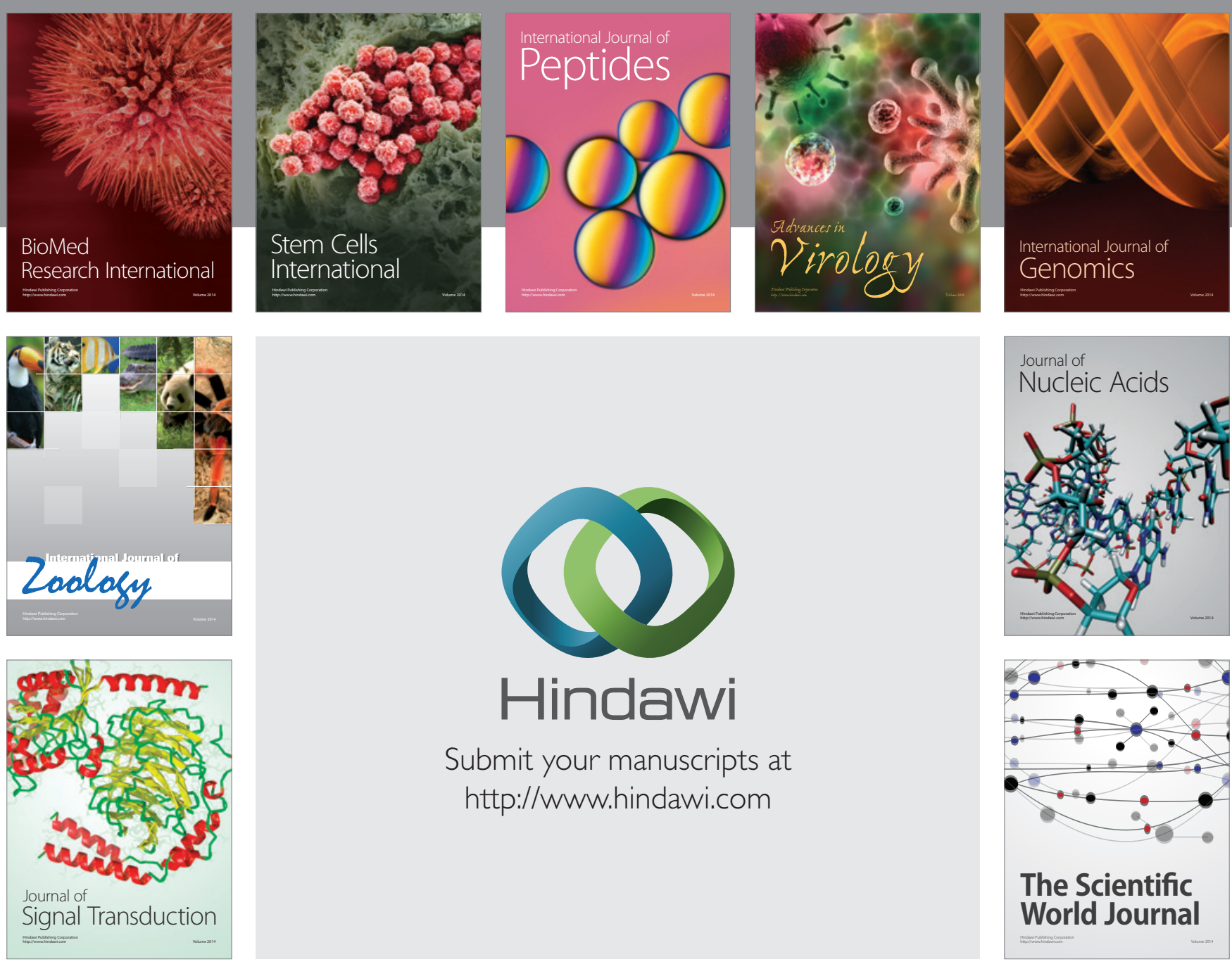

Submit your manuscripts at

http://www.hindawi.com
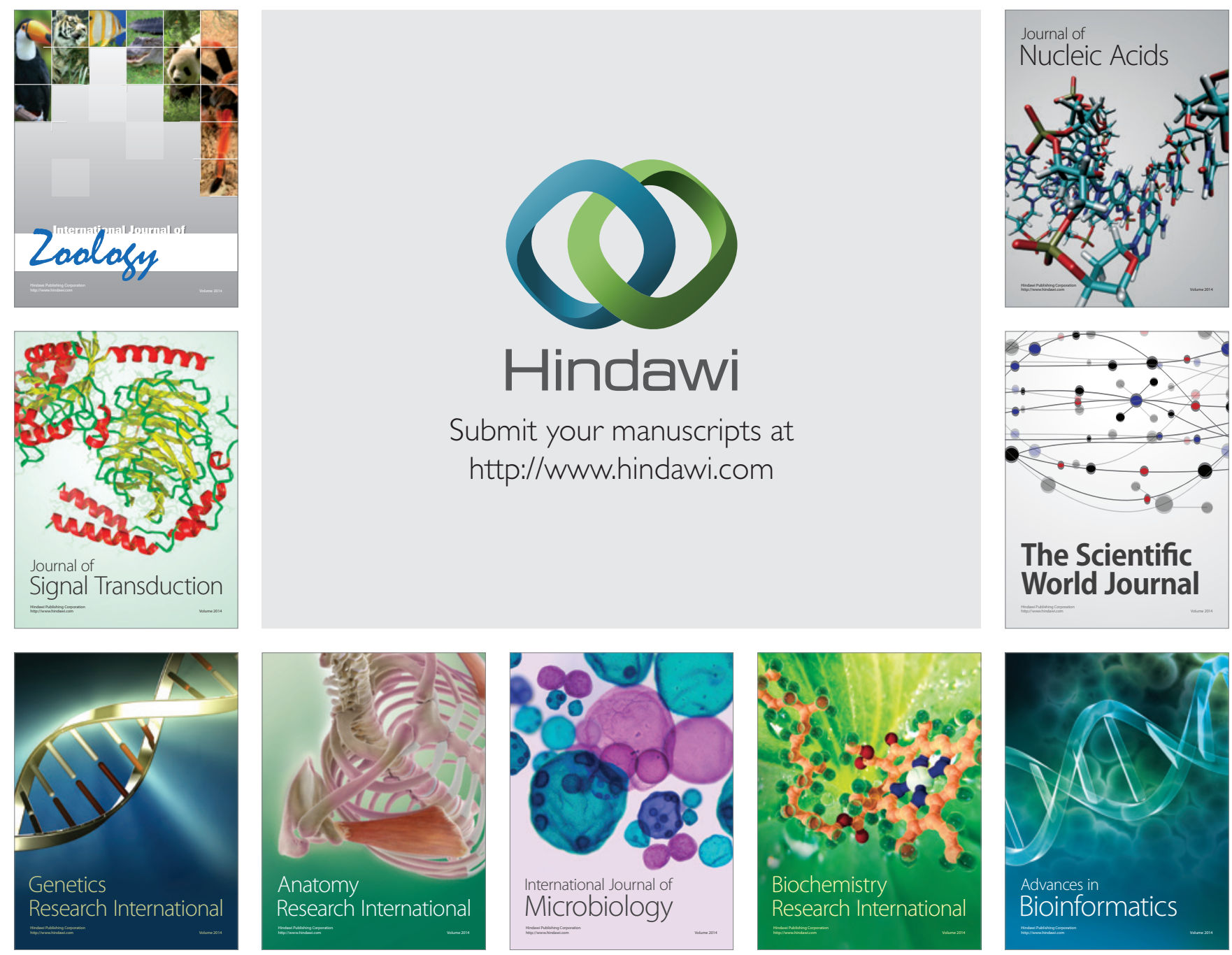

The Scientific World Journal
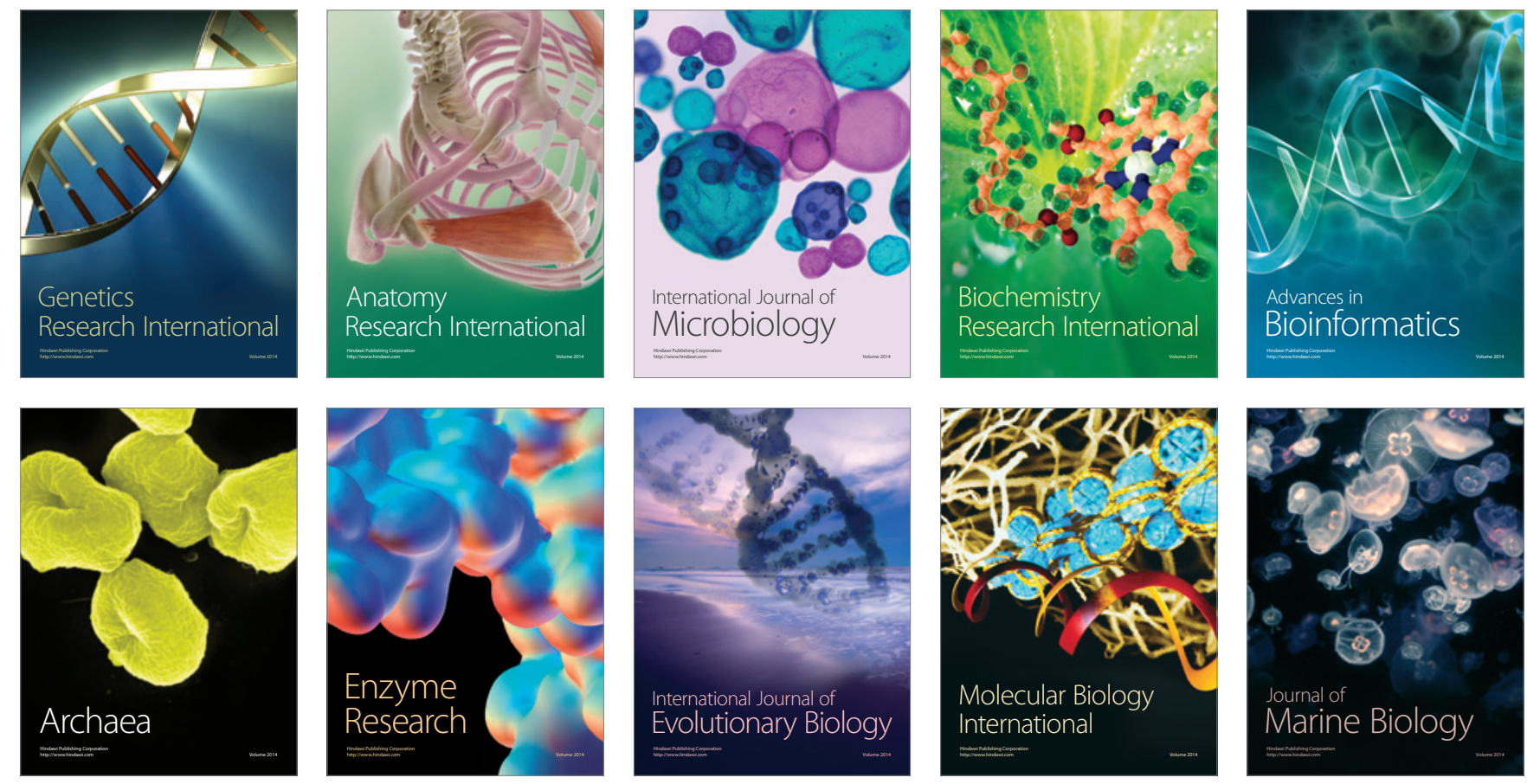